\title{
El rancho de la vida-the ranch of life - a treatise to address the old and outdated recovery standards and practices
}

\section{Opinion}

The epidemic of opioids in maine and beyond, what can be done? What should we do, and what can we do? This is a monograph that takes into consideration multiple attempts at battling addiction at the personal level, and recently works alongside many others in the same battle. We will be starting with the insanity of emotional precursors that exacerbate addiction. We will address the constant threat of user's guilt, blame, self-harm, personal ambivalence, cognitive and psychiatric responses, or lack of. Then, moving up to the parties of responsibility, the corporate pirates of addiction recovery for-profit providers; the PCP for-profit level, the local for-profit government and for-profit public view, (Stigma), the state government for-profit level, and all responsible for-profit federal levels, and all scientific endeavours as per Addiction Sciences, Addiction Medicine and Drug Addiction policy.

Never said, written or recognized is a real, understandable and implemental, Recovery Policy like our attempts at addiction and drug policies like 'The War on Drugs' (past and present addiction Treatment alternatives?) our Huge monolithic Government and society currently has in place. Have you ever seen an Addiction Recovery Policy? Not until last year came The Comprehensive Addiction and Recovery Act (CARA) of 2015. The current history of addiction recovery tells us that we have failed miserably at helping our population recover properly from alcohol, drugs, sex addiction, gambling problems and every other activity that provides human beings with a false sense of power, and a true feeling of a rush, or of an intense life force, coming at us too fast, too strong, and all of us wind up, 'battling addiction' instead of treating both our physical selves, and the underlying emotional issues that have clearly gone awry. This self-actualization is a way to enforce a failing system because we as helpers like to blame. We have not taken into consideration that these people (our sons and daughters, our mothers and fathers, our wifes and husbands, brothers and sisters) are all quite human and quite fallible when faced with a substance or activity that challenges the very core of our humanity and living as a healthy human being. The feeling of power and confidence, when all else has not, made us feel that way, and of course, the real sense of, 'fuck it', when we feel that we are beaten down and abused by ourselves. That is never talked about. We want to feel good. When life gets in the way, we imbibe. Ok, so we as helpers have failed at assuming that 'we' can 'fix you'. We know or are starting to know, that only you, the human inside your addiction, is capable of 'fixing' a problematic behavior that was once fun and now rules our lives. We have to want to get better. This 'faith' in oneself is at the very essence of stopping addiction permanently. I know, as I had lost faith in myself and faith that control of usage is lost, gone and we simply fold. Then as our addictive obsession continues, "taking everything from our lives (obsessive, compulsive behaviors), that always leads to vastly uncharted, negative consequences, start to pile up. Loss of self, loss of money, loss of home, loss of work, loss of pride, loss of joy, loss of comfort and of course loss of loved ones, and the love and loss of ourselves.
Volume 3 Issue 6 - 2017

Jamie Lebish

El Rancho De La Vida, USA

Correspondence: Jamie Lebish, El Rancho De La Vida, Kings Wood Park, South Portland, Maine, USA, Email jamielebish@gmail.com

Received: July 17, 2017| Published: August 07, 2017

\section{The recent news on narcan}

I have recently witnessed, first hand, people lying on the side of the road, dumped off by scared friends or families in front of my current place of business, at Milestone Detox. I have been by their side as police and first responders try to resuscitate a non-alive human being. They work feverishly and patiently to assess the heartbeat or lack of, then administer Narcan by way of "The Kit". The Narcan kit once pushed into a lifeless body miraculously brings it back to life, and most of the time, that person is really angry that they were brought back (from the dead). These addicts have had enough, and really want to die as a precursor for living in the hell that they have been living in. This is another way for providing a needed resistance to death as an alternative of the ravages of addiction. "Dope/Alcohol" (insert addictive behavior) "has control over me and now I am fucked". This is the top of the rabbit hole, as now, a whole new addiction industry has been built around, "We can fix it, if you can pay X amount for our modality of treatment and recovery". Institutions and Treatment centers started to pop up everywhere (When, names, types, outcomes?). There are many large and small confusing, profit oriented systems of cessation of addiction, not recovery care from addiction. Recently, I called around to Suboxone providers in the Portland area, for the purpose of finding barriers to treatment, (at the provider level). Every Suboxone provider I called told me; 'we could fit you in, in 2 weeks' "2 weeks, really"? "What do I do now, I am calling now"? 'All I need is for you to bring in $\$ 350.00$ cash and we can get you started on Suboxone'. The argument being that: you were able to pay for your habit, so why can you not come up with the money that will save you? I am sorry to say that this standard of practice among providers is real and dangerously profit-oriented from the get go. Why not $\$ 100.00$ or why not ask for insurance? Why don't these providers say to the suffering person, "we will take you today, and we will work out the cost when you get here and become stable"? These are just two examples of barriers to treatment. Or, call any clinic or provider in your area of your choice. Ask them 'I want to start on medication assisted therapy' or simply ask when you can be seen. They will most likely tell you that they have waiting list, and they only take cash or Maine Care. Addicts cannot wait. They are dying and they are calling out if sheer panic and on the last vestiges of hope that they can receive 
sanity help. The argument being that: you were able to pay for your habit, so why can you not come up with the money that will save you? I am sorry to say that this standard of practice among providers is real and dangerously profit-oriented from the get go. This is when profiting from addiction starts, at the beginning of recovery with hospitalization for detoxification.

When I went through Detox, at a for-profit hospital and a few private for-profit detoxes, I only knew that this was the first step, (proven medically that a Human Being must detoxify the body of poisons, before any real recovery can begin). Then the levels of recovery and aftercare start with the very lucrative business of owning and operating a Sober Home. Or, there is Intensive Outpatient Centers (IOP) for- profit, and Long term Treatment for-profit and other aftercare models, such as groups and therapy, all of which need funding(forprofit), except AA/NA and all self- help groups meetings (self-funded through passing the basket). For-Profit Addiction treatment is killing us, (Put in Statistics). Why do we need to profit from the very thing that helps people get off deadly medications prescribed by physicians, or as it seems to go we turn to street drugs because we still feel pain (The science of pain) increasing, with more Opioid levels increasing. Yet doctors have limits? Then they just stop prescribing opiates for pain. This is a gateway into the world of self medication. We have gotten recovery wrong. We as caregivers can be the best and sometimes the worst caregivers, because we are not people in power(money and status), we are in recovery we have experienced loss and devastation because of addiction, We indeed may not know how or why we are to counsel or manage something that is inherently impossible to manage.

Addiction is a beast from within. It implies a suffering and a state of loss, one of total confusion, and it is at the very core of being an addict. This impact is 'not important' in the public perception of addiction today. We as 'recovery helpers' have failed miserably. We have tried everything that comes to us as a possible treatment, when we goddamn know better. The addict, the human being that is sitting in front of you is at a loss of explanation because addiction, at any level (mild, moderate or severe, really?) is traumatic. Addiction is trauma, stemming from other 'mental health' issues, forming together to complete a shit storm in our brain. 'Put down that drink or it will kill you', sounds very attractive to a human being who is suffering a kind of madness from within. The addiction professional in recovery would know this. I put quotes around 'mental health diagnosis' because initial diagnosis is not a rational way of determining a sound 'Mental Health' diagnosis from something we have not even begun to understand, no less, try to assess. Trauma forms different pathways in the brain to "feel better" or to feel nothing at all; because "I cannot handle any of this" I have tried and tried (Science). Think about it, every time I have assessed a client and every case I have read about says that, we are to write down separate and distinct mental health diagnoses or the client self-reports anxiety, depression, PTSD, ADD and ADHD, all diagnosis that were assumed, while the client was most likely much younger, or not sober, nor at all rational $99 \%$ at the time of their diagnosis. (Find science). I know. I was always high and irrationally defiant at all of my therapy appointments and psychiatric assessments, and when after checking into 10 separate detoxes over time, (all profit based), because I had to be assessed? Life seemed too unfair and my dreams and hopes were dying in front of me. That is why I used, eventually to acknowledge that it's ok that I'm a failure, as long as I get through the day, with my medicine. The high or getting well is really described as "feeling normal, for me". That was a big issue for me as I did not know, and no one was able to tell me, what normal for me, was when I was addicted to heroin, I rarely got "high", I intended to get 'well'. Getting high was a huge plus, if at all possible. We also never talk or talk about what initially started our recreational use. My mind felt better, in the first place I felt warm and comfortable in my own body for the first time.

A classic example is why we do not talk about how our addiction started, instead we ask, what are you taking now, how much, and how often? At the end of my run, or at any point along my addiction, I did not ask" hey dude, what is it cut with? We do not care anymore. Addicts do not care what they put in them; we just want to feel like everything is OK. Do you believe that any of us, when we were active users, could or would put our dope in a gas spectrometer? Hell no, we are all secretly hoping this shot will make it all go away. My point is that the whole realm of Addiction recovery has to be re-written through the eyes of people who have recovered. Only those folks know how insanely hard and uncomfortable recovery is, how it was for them, and life may be forever dull, and for sure we would have no fun ever again. Were we having fun? Was this all worth it? Skewed awful thinking yes, it is also true, yes it is. Ask any addict.

We need a new way of thinking and implementing the recovery process. The one idea that has always been at the back of my sick mind, until I became not sick, was the idea that we as addicts need a place to call home or sense of being 'at home', where we as addicts, and we as helpers are on the same page, and in the same area 24-7. Where we become one with the knowledge of how, why and what does it take. And now that we have put in the grueling torment of recovery time, we need a home base for others recovering from a life changing event that is killing us one by one every day. There were 367 deaths from opiates in 2016 in Maine alone. El Rancho Del Viva is that place. The Ranch of Life is where human beings can get back their humanity, and eventually be there for the next addict that comes into our lives. We want to care for the sick and mind-altered addicted persons because of skewed thinking, so that they can care for the next person and so on. One addicts helping another, while sharing important life coping skills that each of us has acquired through sobriety. We have learned to live clean then schooling ourselves, and then working within professional ties. One person may come in with knowledge of cuisine. Why do we not celebrate that person by giving them a place to recover (to get back) one's life, but the 2.0 version of their life. The Ranch is the only avenue bold enough to be a real stepping stone for starting recovery and being recovered, through feeling empowered that you have now taken a choice to get well, and look forward to a life that matters. We want all of these people at The Ranch. We will not tolerate violence. That is the only line we will draw. If you have anger management problems, most likely you are not a violent person. You have become angry because inside, you know you are better that that.

El Rancho De La Vida will be a Non-Profit recovery and Life Ranch with $100+$ acres of Farmland, woods, fields and a real working ranch with cattle and cowboys, Recovering cowboys living at a place that does not punish or discriminate because of your lust for passion. That is a human quality, passion that is. We need to adapt passion for inner peace through drugs, alcohol and other self empowering needs, so that we can always look forward to a rewarding feeling, when we do good works. The Ranch will be staffed by anyone in recovery who has battled with and won. We are recovering addicts who want to put other's addictions before them. That includes Addiction Specialists like medical doctors who are in recovery and have rejoined their clinical colleagues, but feel out of place at a typical hospital or 
private practice. Nurses who are in long term recovery who have a true passion for being where they do their best work, and counselors and administration staff in recovery are the front line workers at The Ranch.

Imagine for a second, one on one counseling on horseback. Or, imagine discussions while walking through fields of gold, without the constraints of modern, clinical buildings that have no personality. Imagine, Snowy afternoons on a ridge with a person beside you that is listening and compassionate, advising only if the person asks for help, or advice. We want to be there for all of us that battle with being inherently human, with its faults, and its immense pleasures. Imagine, for example, the feeling of being in love. That is a human pleasure that most of us have turned off long ago, or forgotten about completely, on our own accord or through the devastating effects of the chemicals and lifestyles we thought would get us through. Then a certain type of magic will occur, totally out of respect for one human, being with another human being that has run head first into a wall of shame doubt and anguish. The entire community will be built around safety, comfort, humane treatment for a disease that does not conjure the word comfort, when thinking about recovery from our previously insane life style. The Ranch is 'the place' I have had on my mind ever since I entered treatment for my heroin addiction. El Rancho De La Vida will be built and hopefully staffed by the very people who can understand the insanity of active addiction. We want to help, and we will make a difference, while not profiting from the pain of another human being.

\section{Acknowledgements}

None.

\section{Conflict of interest}

The author declares no conflict of interest. 